\title{
Statistics Analysis on Soil Reduction Activity in Grizzly-under-Materials Discharged from Recycling Plant of Waste Asphalt Blocks
}

\author{
Milkos Borges CABRERA*, Tomoaki SATOMI* and Hiroshi TAKAHASHI* \\ * Graduate School of Environmental Studies, Tohoku University, Sendai 980-8579, Japan \\ E-mail:combigra2013@gmail.com
}

\begin{abstract}
Waste asphalt blocks from construction sites are usually processed in the recycling plants to be used as recycled asphalt aggregates. These materials are usually fed into the grizzly to remove the soils attached on their surfaces. At present, grizzly-under-materials (GUM) does not satisfy the required standard value for soil contents. In 2009, we proposed the equipment to remove the soils from GUM. This equipment was able to reduce the soil content in the GUM, but the efficiency was not so high. Then, in 2013, a process of redesigning this equipment was carried out; where a vibration device was added to reduce the pipe inclination angle and to increase the processing time of materials inside the apparatus. The equipment performance had an opposite behavior from 2009's experimental results to 2013's experiment results, when the water content in the GUM was changed from $3 \%$ to $5 \%$. That is, it was necessary to analyze the main factors that influence on equipment performance. In this study, the experiments were carried out with changing the water contents. It was found through this research that soil reduction activity, using the screenless separation equipment not only depends on the soil particle distribution (\% of clay and silt) contained in GUM and the moisture content in the soil when is mixed with GUM. Specific surface area and water absorption of GUM and temperature also have influence on the mentioned activity.
\end{abstract}

Keywords : Waste asphalt blocks, recycled asphalt aggregate, grizzly under material, soil content

\section{INTRODUCTION}

Nowadays, every year, many roads are damaged by heavy traffic and weather. These are two main factors that cause the emergence of cracks on the road surface. Usually governments of many countries dedicate large amounts of money to support and guarantee reparation actions over roads. Road repair generally consists of stripping off the road surface, that is the asphalt mixture, and pouring new asphalt concrete at the same place from where the stripped asphalt concrete was removed. The stripped asphalt blocks are known as "waste asphalt blocks". Waste asphalt blocks are usually transported to the processing plant and are crushed to use as recycled asphalt aggregates. The process inside the processing plant is schematically shown in Figure 1 Ref. [1].

In Japan, every year a large amount of waste asphalt blocks are generated from road reparation. For example, in 2005 there were about 26,310,000 tons of stripped asphalt blocks to process; $60 \%$ of this amount was "Grizzly-over-materials" GOM and was used as recycled asphalt aggregates because they generally satisfy the required standard values shown in Table 1, but the remaining 40\% was "Grizzly-under-materials" GUM and was used as roadbed material, because they do not satisfy the required value for Amount of Soils, shown in Table 1 Ref. [3].

Recycled asphalt aggregates are useful alternatives to virgin materials because they reduce the use of virgin aggregates and the amount of virgin asphalt binder required in the production of hot mix asphalt (HMA) Ref. [4]. The most economical and optimal use of recycled asphalt aggregate is in asphalt mixtures Refs. [4].

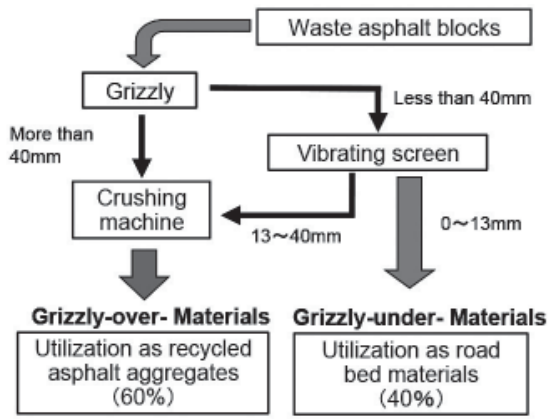

Figure 1 Process inside the processing plant

Table 1 Quality of asphalt mixture

\begin{tabular}{llll}
\hline Items & $\begin{array}{l}\text { Content of } \\
\text { asphalt [\%] }\end{array}$ & $\begin{array}{l}\text { Needle } \\
\text { penetration for } \\
\text { asphalt }\left(25^{\circ} \mathrm{C}\right) \\
1 / 10 \mathrm{~mm}\end{array}$ & $\begin{array}{l}\text { Amount of } \\
\text { soils [\%] (less } \\
\text { than 75 } \mu \mathrm{m})\end{array}$ \\
\hline $\begin{array}{l}\text { Value of } \\
\text { Standard }\end{array}$ & $\begin{array}{l}\text { More than } \\
3.8\end{array}$ & More than 3.8 & Less than 5 \\
\hline
\end{tabular}

Therefore, the usage of GUM, as recycled asphalt aggregates to produce asphalt concrete, it is the best option for this material.

One way to reduce the amount of soils in GUM is to decrease the mesh size of the vibrating screen. Nonetheless, at the same time, the reduction of mesh size in the vibrating screen increases the possibility of clogging in a short time. Consequently, most of 
the processing plants in Japan use vibrating screens with $13 \mathrm{~mm}$ mesh size empirically to avoid the clogging of the screen. From this situation, it is necessary to find another way or to create a screenless equipment to reduce the soil content in the asphalt material to process.

In 2009, a new equipment to reduce the soil contents in GUM was developed Ref[5]. The equipment was able to reduce the amount of soil in the GUM, but its performance decreased with increasing the water content in the GUM. Therefore, it was necessary to improve the equipment performance. In 2013, a process of re-designing the screenless apparatus was conducted Ref[5]. In this process, a vibration device was added to the equipment and the inclination angle of the pipe was reduced. The performance of the newly screenless equipment increased compared to the previous one. On the other hand, when the water content in GUM was increased from 3\% to 5\%, the equipment performance increases, then that behaviour was opposite from the results related with previous equipment.

From this mentioned scenario, it was necessary to spend more effort to understand the behavior of the equipment performance. Even the general characteristics of newly proposed equipment and previous apparatus were different; it is believed that the main reasons to obtain an opposite behavior of the equipment performance was related with the characteristics of GUM and the soil attached on its surface.

\section{OBJECTIVES AND SCOPE}

From previous fact, it is necessary to define the main factors which have an important influence on equipment performance. It was proved that the equipment performance increases with decreasing the stickiness capacity of soil contained in GUM Ref. [5]. Most of the properties and chemical reaction in soils is caused by the presence of clay. Clay particles have a vastly great tendency to stick. The high reactivity of clay particles results from their much greater specific surface area than sand and silt particles because the secondary mineral species that comprise the clay fraction often have high surface charge Ref. [6]. Of course, moisture content in soil also has a high influence on its stickiness capacity. Therefore, the stickiness of the soil mainly depends on its particle size distribution and moisture content. The particle size distribution of a specific soil does not change so much, but moisture content in the soil depends on the weather condition at construction site. Hence, the moisture content in the soil contained in GUM has a great influence on equipment performance.

Therefore, the main objective of this study is to define the factors that decide the moisture content of soils when it is mixed with GUM at construction sites and to carry out a statistic analysis of the equipment performance, after setting the experimental condition, changing the water content in the material to process. Temperature will be also changed in the laboratory.

\section{EXPERIMENTAL APPARATUS}

The newly proposed screenless separation equipment was composed by a large compressor, a suction machine, a vibration device and a main pipe. The large compressor was used to blow the swirl air flow into the pipe from a tangential direction with the purpose to separate the fine soil particles from the GUM. The suction machine was used to suck the removed fine soil particles from the GUM. The vibration device (cam and motor) was used to produce a controlled vibration in the equipment, changing its

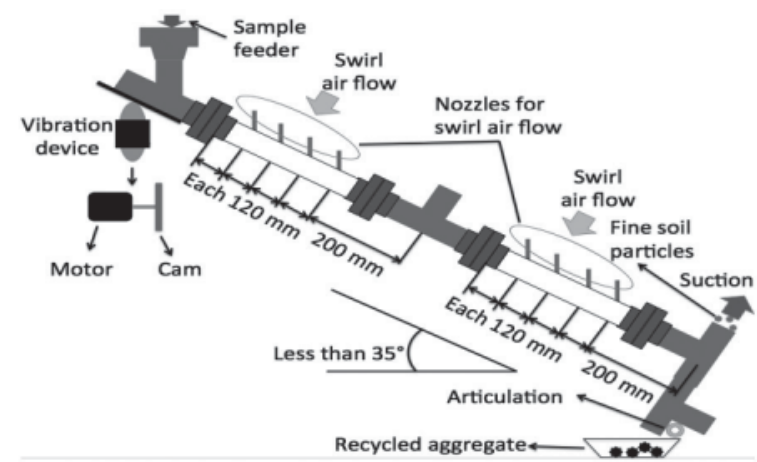

Figure 2 Schematic diagram of the newly proposed separation equipment.

amplitude and frequency. The main pipe of the equipment was used to support the movement of the GUM and the separation process of the fine soil particles from GUM. Figure 2 shows the schematic diagram of the screenless separation equipment.

\section{EXPERIMENTAL PROCEDURES}

The experimental study on determination of the characteristics of GUM without soil content (GUM-WS) was carried out as follows:

1. A sample of GUM $(15,000 \mathrm{~g})$ was washed in the laboratory, until the whole particle soils were removed from the surface of the material in question.

2. Determination of particle size distribution of GUM-WS, was carried out taking into consideration (JIS A 1102, 2014) Ref. [7].

3. Determination of the specific surface area of GUM-WS, was carried out taking into consideration the formula of Manual: MS-2 Asphalt Mix Design Method. Asphalt Institute ( $7^{\text {th }}$ Edition, 2015) Ref. [8].

4. After determining the particle size distribution of GUM-WS, this material in question was divided in fine aggregates and coarse aggregates, with the objective to determine them water absorption.

5. Determination of water absorption of the coarse aggregates, obtained from GUM-WS, was carried out taking into consideration (JIS A 1110, 2006) Ref. [9].

6. Determination of water absorption of the fine aggregates, obtained from GUM-WS, was carried out taking into consideration (JIS A 1109, 2006) Ref. [10].

7. Determination of water absorption of the whole GUM-WS sample $(15,000 \mathrm{~g})$.

The experimental study on determination of the characteristics of soil attached on the surface of GUM was carried out as follows:

1. Several samples of GUM (1000g) were washed in the laboratory.

2. Soil particles suspended in water were poured in a metal container.

3. Those metal containers were placed into the oven at $110^{\circ} \mathrm{C}$, to collect the soil.

4. Determination of liquid limit of the collected soil was carried out taking into consideration (JGS 0142, 2009) Ref. [11].

5. Determination of plastic limit of the collected soil was carried out taking into consideration (JIS A 1205, 2009) Ref. [12].

6. Determination of shrinkage limit of the collected soil was carried out taking into consideration (JGS 0145, 2009) Ref. [13]. 
7. Determination of particle size distribution of the collected soil was carried out taking into consideration (JIS A 1204, 2009) Ref. [14] and (JGS 0051, 2009) Ref. [15].

The experiments on reduction of soil content in GUM, after setting the same value of each decided parameter that has influence in equipment performance were carried out as follows:

1. 3 samples of GUM-WS (2057g dried mass) and 3 samples of soil (143g dried mass) were dried in the oven.

2. Each dried sample of GUM-WS (DSG) was mixed with one of the dried sample of soil (DSS), to obtain 3 mixed samples of GUM-WS and soil (2200g dried mass). Mixing those amounts of GUM-WS and soil, it was set at $6.5 \%$ the soil content in the mixture (SCM) of GUM-WS and soil.

3. A load of $15 \mathrm{~kg}$ of aggregates for 24 hours was placed on each mixed sample of GUM-WS and soil, to simulate the storage conditions at construction site. In Figure 3 is shown a mixed sample of GUM-WS and soil. After 24 hours the load is removed.

4. The pipe inclination angle (S) was set at 15 degrees.

5. The large compressor of the equipment was started.

6. The suction machine of the equipment was started.

7. The vibration device of the equipment was started. The frequency (F) was set to 260 RPM and amplitude (A) was set to $1 \mathrm{~cm}$.

8. A $25^{\circ} \mathrm{C}$ of temperature was set in the laboratory.

9. A certain amount of water to pour into mixture (AWM) was decided to prepare a mixed sample of GUM-WS, soil and water, with the goal to obtain a decided water content respect to the total mass (WTM) and respect to the amount of soil (WAS). Table 2 shows 2 examples of mixed sample of GUMWS and soil.

10. Each mixed sample of GUM-WS and soil with water was fed into the equipment twice, to simulate two suction places.

11. Soil content in every processed mixed sample of GUMWS and soil by the equipment was measured taking into consideration the Japanese Industrial Standard (JIS A 11032014) Ref. [16].

12. The final soil content in every test with the same water content in the mixed samples of GUM-WS and soil was calculated by the average of the three obtained soil contents in step 11 .

13. A difference between the initial soil content and the final soil content after processing, was calculated for checking the capacity of the equipment to reduce the soil content in the mixed sample of GUM-WS and soil.

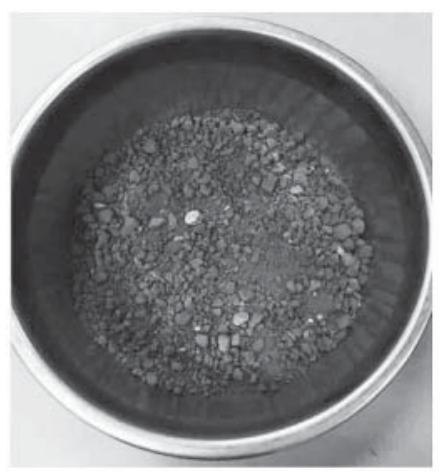

Figure 3 Mixed sample of GUM-WS and soil.
Table 2 Preparation of mixed sample of GUM-WS and soil (4 first samples)

\begin{tabular}{ccccccc}
\hline $\begin{array}{c}\text { DSG+ } \\
\begin{array}{c}\text { DSS } \\
(\mathrm{g})\end{array}\end{array}$ & $\begin{array}{c}\text { SCM } \\
(\%)\end{array}$ & $\begin{array}{c}\text { DSG } \\
(\mathrm{g})\end{array}$ & $\begin{array}{c}\text { DSS } \\
(\mathrm{g})\end{array}$ & $\begin{array}{c}\text { WAS } \\
(\%)\end{array}$ & $\begin{array}{c}\text { AWM } \\
(\mathrm{g})\end{array}$ & $\begin{array}{c}\text { WTM } \\
(\%)\end{array}$ \\
\hline 2200 & 6.5 & 2057 & 143 & 5.0 & 7.15 & 0.325 \\
\hline 2200 & 6.5 & 2057 & 143 & 10.0 & 14.30 & 0.650 \\
\hline
\end{tabular}

14. The procedure was repeated from step 1 to step 13, with the goal to increase the water content in the mixed sample of GUM-WS and soil, as it is shown in Table 2. Water content in the mixed sample of GUM-WS and soil was changed by $5 \%$ respect to the soil mass, but from water content equal 50\%, it was changed by $10 \%$ respect to the soil mass (the experiments were carried out all the time, with the same sample of GUMWS and soil).

\section{EXPERIMENTAL MATERIALS USED IN THIS STUDY}

To carry out the study on reduction of soil content in contaminated GUM, actual GUM was used. They were obtained from Sendai Asphalt Plant of Maeda Road Construction Co., Ltd. It was proved from previous experiments that most of GUM did not match the required value for Amount of Soil shown in Table 1 (JRA, 1992). It is easy to watch soil particles attached on the surface of the aggregate. Those soil particles were removed from the contaminated GUM and collected to start the experiments. The collected soil has brownish color.

\section{RESULTS AND DISCUSSION}

\subsection{Soil properties}

Table 3 shows the percentage of clay, silt, sand and gravel that makes up the soil attached on the surface of GUM.

Figure 4 shows the four possible states for soil, the water contents at the boundary of these states are known as Atterberg limits; between the solid and semisolid states is shrinkage limit, between semisolid and plastic states is plastic limit, and between plastic and liquid states is liquid limit.

Table 4 shows the Atterberg Limits of soil used in the

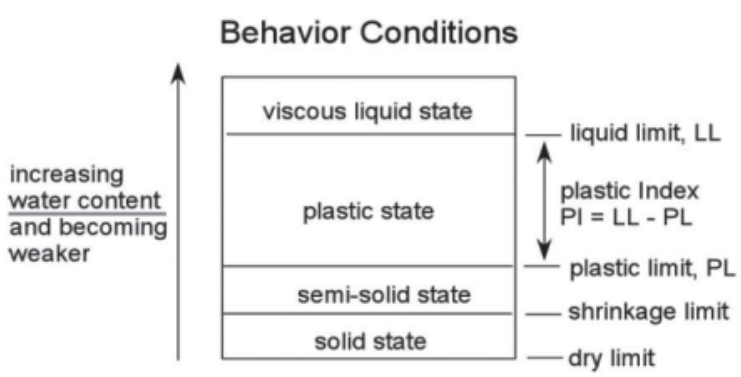

Figure 4 Atterberg Limits and Soil States.

Table 3 Soil composition

\begin{tabular}{cc}
\hline Kind of particles & Soil composition \\
\hline Clay (less than $5 \mu \mathrm{m})$ & $1.2 \%$ \\
\hline Silt $(5 \mu \mathrm{m}-75 \mu \mathrm{m})$ & $93.6 \%$ \\
\hline Sand $(75 \mu \mathrm{m}-2000 \mu \mathrm{m})$ & $5.2 \%$ \\
\hline Gravel $($ more than $2000 \mu \mathrm{m})$ & $0 \%$ \\
\hline
\end{tabular}


Table 4 Atterberg Limits of Soil to use in the experiments.

\begin{tabular}{cc}
\hline Atterberg Limits & Soil composition \\
\hline Liquid Limit (\%) & $37.0 \%$ \\
\hline Plastic Limit (\%) & - \\
\hline Shrinkage Limit (\%) & $26.9 \%$ \\
\hline
\end{tabular}

experiments

\subsection{GUM-WS properties}

After determining the particle size distribution of GUM-WS, the specific surface area of GUM-WS was calculated. It was obtained from Eq.(1) shown in Manual MS-2 of Asphalt Institute Ref. [8].

$$
S A=2+0.02 a+0.04 b+0.08 c+0.14 d+0.3 e+0.60 f+1.60 g
$$

Where, $a, b, c, d, e, f$ and $g$ represent the percent of total aggregates passing the $\# 4, \# 8, \# 16, \# 30, \# 50, \# 100, \# 200$ sieves respectively. The specific surface area of GUM-WS was calculate by Eq. (1) and obtained as follow.

$$
S A=8.11 \mathrm{ft}^{2} / \mathrm{lb}=1.66 \mathrm{~m}^{2} / \mathrm{kg}
$$

To determine the water absorption (WA) of GUM-WS, first, it was necessary to separate the coarse aggregates from fine aggregates that make up the materials. Table 5 shows the obtained experimental results.

\subsection{Experimental test results}

To guarantee the success of reduction activity of soil content in the GUM, it is necessary to control the rate of suction of the equipment.

Rate of suction: It is the capacity that the screenless separation equipment has to reduce the initial soil content in the contaminated GUM, that is, the difference in percent between the initial soil content before the process and final soil content after the process inside the apparatus. This parameter will be measured in \% Ref. [5].

Rate of suction is the most important property to check in the screenless equipment, while this parameter increases, the apparatus will be able to reduce even more the initial soil content in GUM Ref. [5]. Afterward finishing the experiments with $25^{\circ} \mathrm{C}$ in the laboratory, the temperature was changed to $15^{\circ} \mathrm{C}$ to check the behavior of equipment performance when change the temperature, because it is know that temperature can change the behavior of asphalt binder contained in the recycled asphalt aggregate. Besides, experimental test results confirmed the utility of the modifications that were carried out in the equipment Ref. [5].

After carrying out an analysis, this team of researchers consider that, the main factors which have a great influence on the moisture content in soil when is mixed with GUM-WS are: water absorption capacity of GUM-WS, specific surface area of GUM-WS, amount of soil attached on the surface of GUM when contain roadbed materials, percent of clay and silt contained in the soil that is contaminating the GUM, temperature at construction site and time from when the water is poured onto the surface of contaminated GUM to the time when recycled asphalt aggregate is fed into the equipment for the process.

Figure 5 shows the percent of soil contained in the mixture of GUM-WS and soil before and after the process inside the equipment. Horizontal dashed-dotted line represent the percent of initial soil content in the mixtures of GUM-WS and soil, before the
Table 5 Water absorption of GUM-WS

\begin{tabular}{ccc}
\hline \multicolumn{3}{c}{ Water absorption of GUM-WS } \\
\hline Fine aggregate (\%) & Coarse aggregate (\%) & GUM-WS (\%) \\
\hline 1.78 & 1.63 & 1.71 \\
\hline
\end{tabular}

Rate of suction

$\mathrm{F}=260 \mathrm{RPM}, \mathrm{A}=1 \mathrm{~cm}, \mathrm{~S}=\mathbf{1 5}^{\circ}$ (Soil NE)
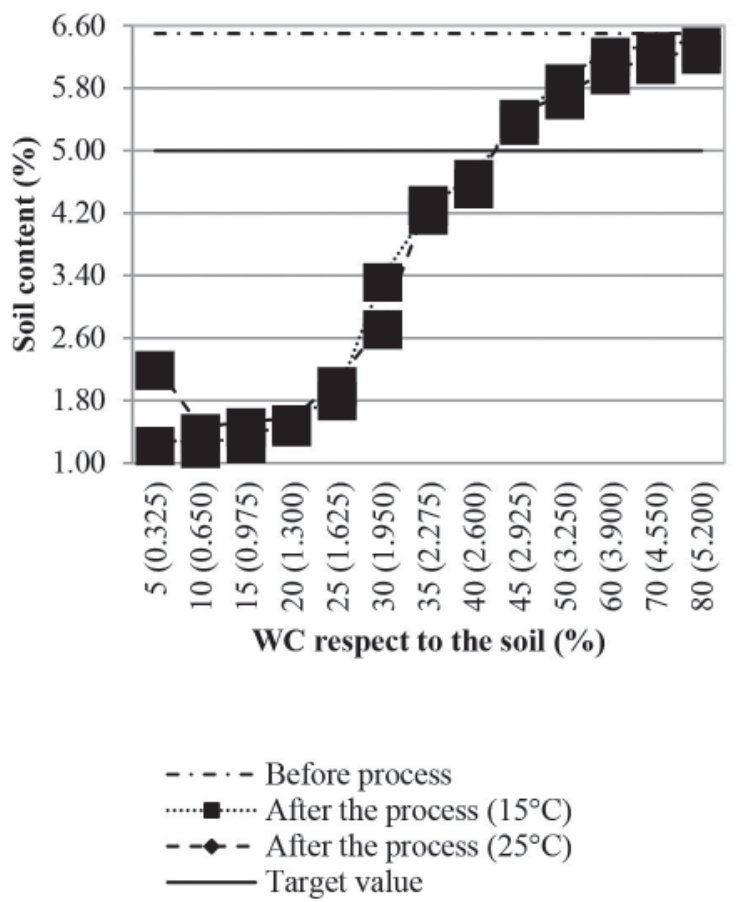

Figure 5 Soil content before and after the process $\left(\mathrm{S}=15^{\circ}, \mathrm{A}=1 \mathrm{~cm}, \mathrm{~F}=\right.$ 260RPM with Temp $=25^{\circ} \mathrm{C}$ and $15^{\circ} \mathrm{C}$ )

process in the equipment, these values are set at $6.5 \%$. While solid horizontal line, dashed and dotted curve represent the Japanese standard specification (5\%), soil contained in the mentioned mixture after the process when the temperature was set to be at $25^{\circ} \mathrm{C}$ and $15^{\circ} \mathrm{C}$, respectively. Values inside the parenthesis in horizontal axis represent the water content in the mixture of GUMWS and soil, respect to the total mass.

Soil content in the mixture to process was set at a fitted value $(6.5 \%)$, in an attempt to understand better the behaviour of the equipment performance. From the experimental results shown in Figure 5, it was possible to conclude that the equipment was able to reduce the percent of soil contained in the mixture of GUM-WS and soil less than $5 \%$, required value from (JRA 1992), from $5 \%$ to $40 \%$ of water content respect to the amount of soil, regardless the temperature in the laboratory. It is also possible to conclude that, soil content in the processed mixture, after the treatment in the equipment, from $5 \%$ to $10 \%$ of water content respect to the amount of soil, tend to decrease regardless the temperature. This fact means that, the equipment was able to reduce more the initial soil content in the material to process when the mixture of GUM-WS and soil contain $10 \%$ of water content respect to the amount of soil than when contain $5 \%$ of water content respect to the amount of soil, regardless the temperature in the laboratory. Besides, in the same mentioned range of water content, the percent of soil contained in the mixture after the process, was lower in case of $15^{\circ} \mathrm{C}$ than in 
Rate of suction (\%) (Soil NE)

$\mathrm{F}=260 \mathrm{RPM}, \mathrm{A}=1 \mathrm{~cm}, \mathrm{~S}=15^{\circ}$

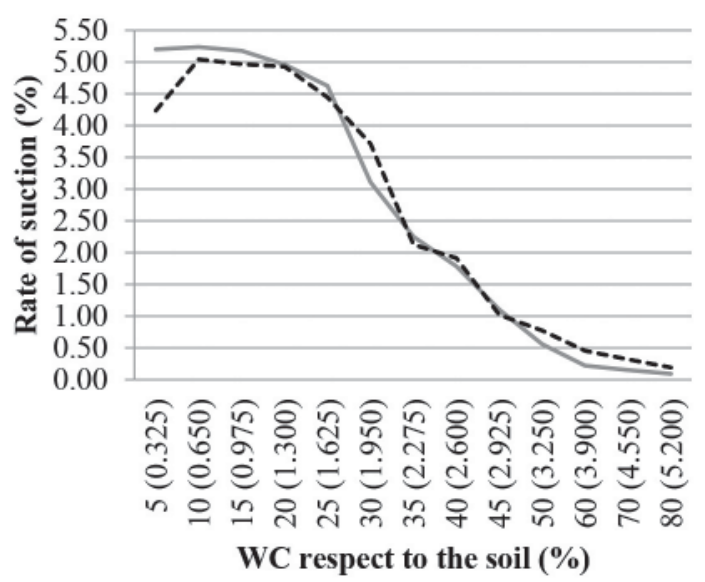

- Rate of suction. Temp $15 \mathrm{C}^{\circ}(\%)$

------ Rate of suction. Temp $25^{\circ} \mathrm{C}(\%)$

Figure 6 Rate of suction $\left(\mathrm{S}=15^{\circ}, \mathrm{A}=1 \mathrm{~cm}, \mathrm{~F}=260 \mathrm{RPM}\right.$ with Temp $=$ $25^{\circ} \mathrm{C}$ and $15^{\circ} \mathrm{C}$ )

case of $25^{\circ} \mathrm{C}$, regardless the water content. On the other hand, the percent of soil contained in the mixture of GUM-WS and soil after the process in the equipment, from $10 \%$ to $80 \%$ of water content respect to the amount of soil, increases regardless the temperature in the laboratory. This fact means that, the equipment performance decreases while increases the water content in the material to process, from $10 \%$ to $80 \%$ of water content respect to the amount of soil, regardless the temperature in the laboratory.

Figure 6 shows the rate of suction of the screenless separation equipment. Black dashed curve represents the rate of suction of the equipment, when temperature in the laboratory is set at $25^{\circ} \mathrm{C}$, while grey solid curve represents the rate of suction of the apparatus when temperature in the laboratory is set at $15^{\circ} \mathrm{C}$.

To carry out a statistical analysis of previous data and determine if there is difference between rate of suction data changing the temperature, first it is necessary to know if they have normal distribution or non-normal distribution. There are significant amount of normality tests available in the literature. Shapiro-Wilk is the most powerful test for all types of distribution and sample sizes Ref. [17]. This procedure calculates a W statistic that tests whether a random sample $\mathrm{x}_{1}, \mathrm{x}_{2}, \ldots, \mathrm{x}_{\mathrm{n}}$ comes from a normal distribution. The statistic is calculated as follow Ref. [18]:

$$
W=\frac{\left(\sum_{i=1}^{n} a_{i} x_{(i)}\right)^{2}}{\sum_{i=1}^{n}\left(x_{i}-\bar{x}\right)^{2}}
$$

Where the $\mathrm{x}_{(\mathrm{i})}$ are the ordered sample values $\left(\mathrm{x}_{(1)}\right.$ is the smallest) and the $\mathrm{a}_{\mathrm{i}}$ are constants generated from the means, variances and covariances of the order statistics of a sample of size $n$ from a normal distribution Ref. [18]. Then, the alpha level $(\alpha)$ will be set at 0.05 , it means that confidence level will be set at $95 \%$. Null hypothesis $\left(\mathrm{H}_{0}\right)$ : the sample data are not significantly different than a normal distribution. Alternative hypothesis $\left(\mathrm{H}_{\mathrm{a}}\right)$ : the sample data are significantly different than a normal distribution.

To carry out the Shapiro-Wilk test, it will be used the software RStudio version 0.99 .887 , to obtain the value of $\mathrm{W}$ and $\mathrm{p}$-value. If p-value is more than alpha level $(0.05)$, we can be $95 \%$ certain that
Table 6 FC, $\mathrm{R}^{2}, \mathrm{~W}$, p-value related with rate of suction.

\begin{tabular}{lllll}
\hline Condition & $\mathrm{FC}$ & $\mathrm{R}^{2}$ & $\mathrm{~W}$ & $\mathrm{p}$-value \\
\hline Temp $15^{\circ} \mathrm{C}$ & $-0.08 \mathrm{x}^{4}+1.08 \mathrm{x}^{3}-4.44 \mathrm{x}^{2}$ & 0.99 & 0.81 & $3.2 * 10^{-8}$ \\
& $+4.87 \mathrm{x}+3.90$ & & & \\
\hline Temp $25^{\circ} \mathrm{C}$ & $-0.11 \mathrm{x}^{4}+1.40 \mathrm{x}^{3}-5.84 \mathrm{x}^{2}$ & 0.99 & 0.81 & $3.1^{*} 10^{-8}$ \\
& $+7.41 \mathrm{x}+2.34$ & & & \\
\hline
\end{tabular}

Table 7 Comparison between serials of rate of suction.

\begin{tabular}{cc}
\hline Parameter & Comparison between the serials of rate of suction \\
\hline $\mathrm{p}$-value & 773 \\
\hline $\mathrm{V}$ & $3.573^{*} 10^{-4}$ \\
\hline
\end{tabular}

the data are normally distributed, then $\mathrm{H}_{0}$ is true. If $\mathrm{p}$-value is less than alpha level (0.05), we can be $95 \%$ certain that the data are not normally distributed, then $\mathrm{H} 0$ is false.

It is necessary to be aware that Shapiro-Wilk test do not perform well for small sample size (30 and bellow) Ref. [17]. The sample size in this study is 13 for every experimental condition, then, it is necessary to increase it. Using the mentioned software, it was obtained a fitted curve for every group of data, with the goal to generate rate of suction of the equipment changing the water content by $0.065 \%$, to obtain 76 values. Table 6 shows, the fitted curve equation (FC), the correlation factor $\left(\mathrm{R}^{2}\right)$, the statistics (W) and the p-value related with rate of suction.

From Table 6, it is possible to notice that there is a good correlation between the obtained fitted curve and the experimental data, because $\mathrm{R}^{2}$ is almost equal to 1 . This fact means, those fitted curves are proper tools to simulate the rate of suctions of the equipment with those experimental conditions, changing the water content. On the other hand, analyzing the p-values, it is possible to realize that they are lower than 0.05 , then each group of values is not normally distributed, so $\mathrm{H}_{0}$ is false. Afterwards, to compare these two groups of data, it is necessary a non-parametric procedure. It will be used the Wilcoxon Signed Rank Test, this procedure is the convenient one to compare two matched and not normally distributed samples, besides this procedure calculates a " $\mathrm{V}$ ", this value corresponds to the sum of ranks assigned to the differences (between two groups) with positive sign Ref. [19]. Then, the alpha level $(\alpha)$ will be set at 0.05 , it means that confidence level will be set at $95 \%$. Null hypothesis $\left(\mathrm{H}_{0}\right)$ : there is no a median difference between two serials of rate of suction. Alternative hypothesis $\left(\mathrm{H}_{\mathrm{a}}\right)$ : there is a median difference between two serials of rate of suction.

In this case, if p-value is more than alpha level (0.05), we can be $95 \%$ certain that there is no a median difference between the two serials of rate of suction, then $\mathrm{H}_{0}$ is true. If p-value is less than alpha level (0.05), we can be $95 \%$ certain that there is a median difference between the two serials of rate of suction, then $\mathrm{H}_{0}$ is false. Table 7 shows, the $\mathrm{V}$ values and $\mathrm{p}$-values related with the comparison between the serials of rate of suction changing temperature.

From the analyzes of the $\mathrm{V}$ values and p-values shown in Table 7 , it is possible to conclude the following. The p-value shown in Table 7 are lower than 0.05 , therefore, there is a median difference between the compared serials of rate of suction, then, $\mathrm{H}_{0}$ is rejected. It means that, from the point of view of statistics, changing the temperature from $15^{\circ} \mathrm{C}$ or $25^{\circ} \mathrm{C}$ the equipment performance changes, for the selected experimental condition ( $\mathrm{F}=260 \mathrm{RPM}, \mathrm{A}$ $\left.=1 \mathrm{~cm}, \mathrm{~S}=15^{\circ}\right)$, with $\mathrm{SA}=1.66 \mathrm{~kg} / \mathrm{m}^{2}(\mathrm{GUM}-\mathrm{WS}), \mathrm{WA}=1.71 \%$ 
(GUM-WS), percent of clay equal to $1.2 \%$ and percent of silt equal to $93.6 \%$ in the soil attached on GUM.

Besides, in previous experiments the newly proposed equipment was tested with different temperature and samples of GUM (different SA and WA) contained the same soil that it is being used in current experiments, with those experimental conditions the equipment performance increases from $3 \%$ to $5 \%$ of water content respect to the total mass of the material to process. But, in current experiments it was set the same temperature and the same SA and WA of GUM, using the same kind of soil, then the equipment performance decreases from around 3\% to around 5\% of water content respect to the total mass of asphalt material to process. Therefore, the fixed parameters also have influence on soil reduction activity, therefore have influence on moisture content of soil when is mixed with GUM.

\section{CONCLUSIONS}

It is still necessary to carry out experimental tests in the laboratory with different samples of GUM and soil, changing the temperature, to understand better the behavior of equipment performance.

Even though, the following main conclusions can be drawn, from the experimental results and analysis described above:

1. Soil reduction activity, using the screenless separation equipment not only depends on the soil particle distribution (\% of clay and silt) contained in GUM and the moisture content in the soil when is mixed with GUM. SA and WA of GUM and temperature also have influence on mentioned activity.

2. From the point of view of statistics there is a difference, between the rate of suction of the equipment when temperature is changed from $15^{\circ} \mathrm{C}$ to $25^{\circ} \mathrm{C}$.

3. The equipment was able to reduce the percent of soil contained in GUM less than 5\%, required value from (JRA 1992), from $0.325 \%$ to $2.600 \%$ of water content respect to the total mass, regardless the temperature in the laboratory.

4. The highest equipment performance (rate of suction equal to $5.24 \%$ ), was obtained with $15^{\circ} \mathrm{C}$ and water content equal to $0.65 \%$ respect to the total mass.

\section{References}

[1] Takahashi H.; Aoki Sh.; Kawada H., "Study on Development of New Equipment for High-Level Utilization of Waste Asphalt Blocks Containing Roadbed Materials", Proceedings of the Joint $9^{\text {th }}$ Asia-Pacific ISTVS Conference and Annual Meeting of Japanese Society for Terramechanics, CD-ROM, (2010).

[2] Japan Road Association (JRA). Engineering guidelines of plant re-pavement. (Japanese), 33 (1992).

[3] Ministry of Land, Infrastructure, Transport and Tourism (MLIT). On the survey of Construction waste in 2005 (Japanese) (2006). [Online]. Available: http://www.ijprt.org. tw/ files/Preparation_of_Manuscripts.pdf.

[4] Copeland A., Reclaimed Asphalt Pavement in Asphalt Mixtures: State of the Practice. Report No. FHWAHRT-11-021, 1-20, 39-41(2011).

[5] Borges Cabrera M.; Satomi T.; Takahashi H.,. Study on recycling of waste asphalt blocks containing roadbed materials using new screenless separation equipment with a vibration device, International Journal of Pavement Research and Technology, DOI: 10.1016/j.jpprt.2017.01.006 (2017).

[6] Strawn Daniel G.; Bohn Hinrich L.; O’Connor George A., Mineralogy and Weathering Processes in Soils, Soil Chemistry, $4^{\text {th }}$ Edition, 145-184, (2015).

[7] Japan Industrial Standard (JIS) A 1102-2014. Method of test for sieve analysis of aggregate (2014).

[8] MS-2 Asphalt Mix Design Method. Asphalt Institute. 7th Edition (2015).

[9] Japanese Industrial Standard (JIS) A 1110-2006. Methods of test for density and water absorption of coarse aggregate (2006).

[10] Japanese Industrial Standard (JIS) A 1109-2006. Methods of test for density and water absorption of fine aggregate (2006).

[11] Japan Geotechnical Society (JGS) 0142-2009. Test Method for Liquid Limits of Soils by the Fall Cone (2009).

[12] Japan Industrial Standard (JIS) A 1205-2009. Test Method for Liquid Limit and Plastic Limit of Soil (2009).

[13] Japan Geotechnical Society (JGS) 0145-2009. Test Method for Shrinkage Parameters of Soils (2009).

[14] Japanese Industrial Standard (JIS) A 1204-2009. Test method for particle size distribution of soils (2009).

[15] Japan Geotechnical Society (JGS) 0051-2009. Method of Classification of Geomaterials for Engineering Purposes (2009).

[16] Japanese Industrial Standard (JIS) A 1103-2014. Method of Test for Amount of Material Passing Standard Sieve $75 \mu \mathrm{m}$ in Aggregates. (2014).

[17] Nornadiah Mohd Razali., Yap Bee Wah (2011). Power comparisons of Shapiro-Wilk, Kolmogorov-Smirnov, Lilliefors and Anderson-Darling tests. Journal of Statistical Modeling and Analytics, Vol.2, No.1, 21-33, (2011).

[18] NIST/SEMATECH e-Handbook of Statistical Methods, [Online]. Available: http://www.itl.nist.gov/div898/handbook/

[19] https://statistic-on-air.blogspot.jp/2009/07/wilcoxon-signedrank-test.html 